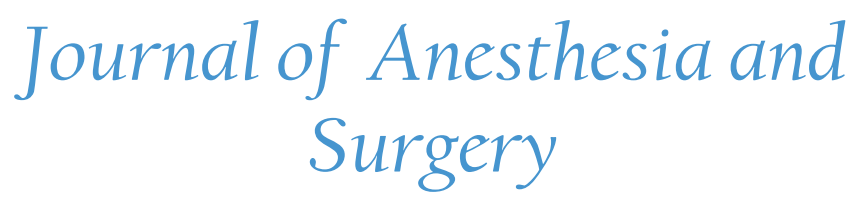

\title{
Ketamine-Propofol (Ketofol) as a Viable Alternative in a Septic Patient with Mediastinal Mass Requiring General Anesthesia for Endoscopic Retrograde Cholangio-Pancreatography
}

\author{
Nisha Rajmohan ${ }^{1}$, Hassy Prakassam ${ }^{1}$, Felix Nelson ${ }^{1}$, Anvar Sadath ${ }^{1}$, Surjya Prasad Upadhyay ${ }^{2 *}$
}

${ }^{1}$ Consultant Anesthesiologist, PVS Memorial Hospital, Kaloor, Kochi, India`

${ }^{2}$ Specialist Anesthesiologist, NMC hospital DIP, Dubai Investment Park, Dubai

*Corresponding author: Dr. Surjya Prasad Upadhyay, Specialist Anaesthesiology, NMC Hospital DIP, Dubai Investment Park, Dubai, United Arab Emirates, Tel: 00971554078445; E-mail: run77in@yahoo.com

\begin{abstract}
Airway compromise and cardiovascular collapse can be anticipated in a patient with mediastinal mass due to aneurysm of ascending and arch of aorta during any stage of anesthesia. Presence of septic shock limits the use of anesthetic agents. The adverse effects of ketamine or propofol are dose dependent and tend to oppose each other cardiovascular effects. The combination of ketamine and propofol may potentially balance each other's haemodynamic adverse effects and therefore, offer a safer alternative for procedural sedation in critically ill. An elderly emaciated lady diagnosed with acute cholecystitis and cholangitis in septic shock had fusiform aneurysm of ascending aorta and arch of aorta with mediastinal compression. She underwent endoscopic retrograde cholangiopancreatogram (ERCP) under total intravenous anesthesia with a combination of propofol and ketamine which preserved spontaneous ventilation. Haemodynamics were maintained with the judicious use of intravenous fluids and vasopressors.
\end{abstract}

Keywords: Ketofol; Sepsis; Mediastinal mass; General anesthesia
Received date: July 27, 2016

Accepted date: August 27, 2016

Published date: September 2, 2016

Citation: Upadhyay, S.P., et al. Ketamine-Propofol (Ketofol) as a Viable Alternative in a Septic Patient with Mediastinal Mass Requiring General Anesthesia for Endoscopic Retrograde Cholangio-Pancreatography. (2016) J Anesth Surg 3(2): 171- 174.

DOI: $10.15436 / 2377-1364.16 .050$

\section{Introduction}

Airway management in a case of mediastinal compression with septic shock is a challenging task to the anesthesiologist in view of the difficulty in maintaining airway, spontaneous ventilation and hemodynamics parameters ${ }^{[1-3]}$. Presence of a mediastinal mass with or without evidence of compression of the mediastinal structures or trachea can result in catastrophes at any time during anesthesia ${ }^{[1-5]}$. We encountered a patient of acute cholecystitis with cholangitis due to biliary obstruction in sepsis for urgent endoscopic retrograde cholangio pancreatography (ERCP) and clearance/stenting of common bile duct (CBD). Incidentally patient was found to have mediastinal mass due to fusiform aneurysm of ascending and arch of aorta causing tracheobronchial shifting to the right. Preservation of the patient own respiration was given priority and ERCP was successfully performed in lateral position under total intravenous anesthesia using ketamine-propofol (ketofol).

Copyrights: (C) 2016 Upadhyay, S.P. This is an Open access article distributed under the terms of Creative Commons Attribution 4.0 International License. 


\section{Case Report}

85 years old women presented to us with acute abdominal pain, vomiting, jaundice for two days. There was no significant medical illness except for hypertension for the last 10 years controlled on angiotensin converting enzyme (ACE) inhibitor and hydrochlorothiazide. On examination she was emaciated (40 $\mathrm{kg}$ ), dehydrated and disoriented, mildly tachypneic (respiratory rate 26 per min), tachycardic (HR-116 beat per min), blood pressure $90 / 60 \mathrm{mmHg}$ without any vasopressor, Blood investigations showed elevated total white cell counts, $\mathrm{C}$-reactive proteins and erythrocyte sedimentation rate (ESR). Liver function tests were normal except for elevated alkaline phosphatase. Renal function tests, amylase and coagulation profile were normal. She had low calcium, potassium and magnesium level, which were corrected. Viral markers, urine routine and blood culture were negative. Ultrasound showed evidence of cholelithiasis with large pericholecystic collection suspicious of gall bladder perforation and features of biliary obstruction. Computed Tomography (CT) scan abdomen showed dilated common bile duct (CBD) and a large lamellated calculus within upper CBD, distended gall bladder (GB) with moderate ascites and bilateral pleural effusions. She was planned for endoscopic ultrasound with ERCP.

On preoperative evaluation it was found that she had difficulty in lying in supine position. She had a systolic murmur in the apex. Chest $\mathrm{x}$ ray showed a mediastinal mass with compression and a massive shift of lower portion of the trachea to the right. (Figure 1)

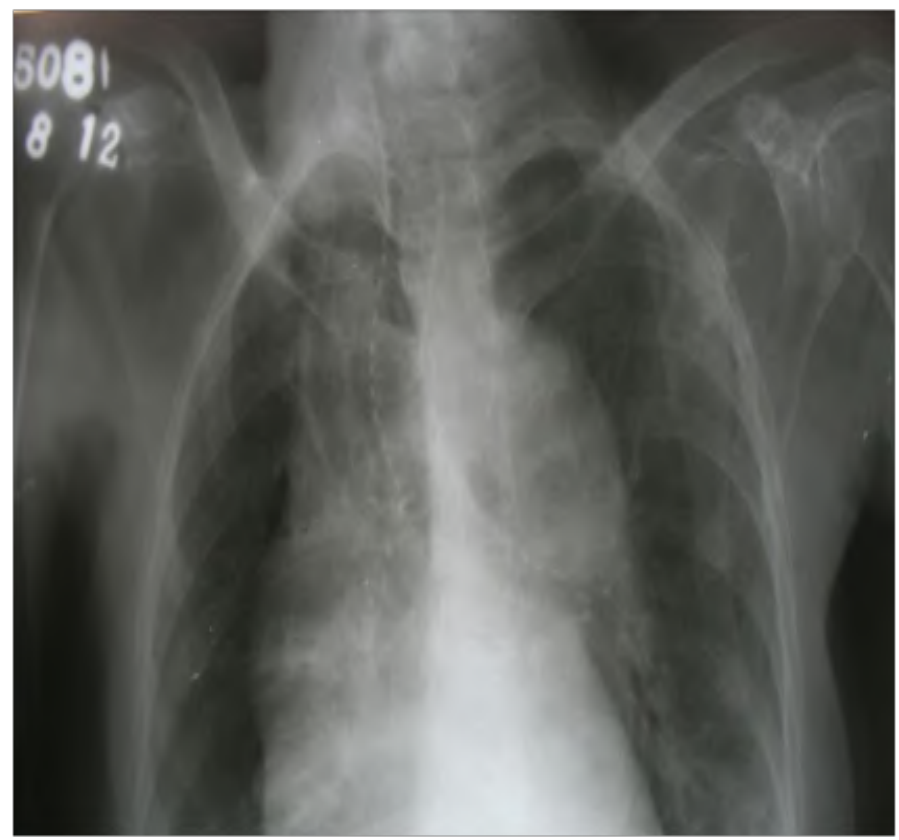

Figure 1: Chest $\mathrm{X}$ ray showing widened mediastinum and tracheo-bronchial shift to right.

ECG showed left axis deviation with multiple atrial ectopics with intermittent atrial fibrillation. An echocardiogram showed normal chamber dimensions, ejection fraction of $50 \%$, no regional wall motion abnormalities, calcified aortic and mitral valves, mitral regurgitation, mild aortic regurgitation. It showed an approximately $5 \mathrm{~cm}$ diameter fusiform aortic aneurysm of ascending and arch of aorta.

She was put on Amiodarone $200 \mathrm{mg}$ thrice daily orally.
We did not have in-house facility for $\mathrm{CT}$ of thorax and she could not be shifted out as her condition deteriorated with ongoing sepsis. The CT abdomen that was done for abdominal symptoms was from another hospital and there was no respiratory symptom and patient was relatively stable to transfer for the CT. Haemodynamic parameters were maintained with noradrenaline infusions. She was diagnosed as acute cholecystitis with acute ascending cholangitis in septic shock.

She was disoriented and unable to cooperate, so general anesthesia on spontaneous respiration was planned for the ERCP. In preparation for general anesthesia, high risk consent was taken, a rigid bronchoscope was kept ready and lateral position maintained. Anesthesia was induced with fentanyl $30 \mathrm{mcg}$, midazolam $0.5 \mathrm{mg}$, glycopyrrolate $0.2 \mathrm{mg}$, propofol $15 \mathrm{mg}$ and ketamine $30 \mathrm{mg}$ and maintained with propofol infusion titrated to maintain spontaneous ventilation. Monitoring included ECG, $\mathrm{SpO}_{2}$, end tidal carbon dioxide monitoring $\left(\mathrm{EtCO}_{2}\right)$ by placing the end of side stream capnograph tube and tapping it near nostril, invasive arterial pressure, central venous pressure (CVP) measured via long arm catheter. Blood pressure was maintained with noradrenaline and vasopressin infusion and intravenous fluids to maintain CVP of $8-10 \mathrm{~cm}$ of water. $\mathrm{O}_{2}$ was provided with nasal cannula. Airway equipment, laryngoscope, endotracheal tube, stylet, bougie, and rigid bronchoscope were kept ready for any urgent airway intervention in case the patient lend up in to crash airway situation.

She underwent ERCP that lasted aproximately $30 \mathrm{~min}$ utes; Cholangiogram showed large calculus within the common bile duct with dilated right ductal system. The calculus was removed after sphincterotomy followed by CBD stenting. Intraoperative course was uneventful. She was shifted back to the ICU in the lateral position. Post procedure, she had hypotension which improved with vasopressors, and intravenous fluids. She recovered gradually over few days and shifted out from ICU on third postoperative day and was discharged home on the tenth post procedural day.

\section{Discussion}

Presence of a mediastinal mass requires a particularly detailed and exhaustive evaluation. Symptoms of difficulty in lying supine and the chest $\mathrm{X}$-ray alerted us to the diagnosis of mediastinal mass with compression. Chest X ray, CT scan, magnetic resonance imaging (MRI) scan, pulmonary function test may prove invaluable $\mathrm{e}^{[1,5,6]}$.

A greater than $50 \%$ reduction in tracheal cross sectional area in a CT scan is associated with increased risk of complications during general anesthesia(GA) $)^{[1,5,6]}$. But we could not have this very valuable information and had to go ahead considering it as an uncertain risk. Whenever possible, procedure should be under local anesthesia. Our patient was disoriented which forced us to plan the procedure under GA. There is always some inherent risk with GA such as ${ }^{[1,4,5,6]}$

\section{Reduction of FRC}

2. Greater compressibility of the airway from the overlying mass due to bronchial smooth muscle relaxation

3. Use of muscle relaxants results in loss of spontaneous diaphragmatic movement which reduces the normal transpleural pressure gradient increasing the compression.

4. Distortion of airway can make intubation difficult. 
In view of all these potential and uncertain risk because of incomplete evaluation, we decided to provide anesthesia by preserving the muscle tone and by maintaining spontaneous ventilation in the lateral position, which is considered safe technique in presence of mediastinal mass ${ }^{[-9-9]}$. Oxygen was administered using nasal prongs at $3 \mathrm{~L} / \mathrm{min}$. Anxiety, pain or high sympathetic tone particularly in this patient may not only pose a risk for rupture of aneurysm but also worsen airflow dynamics by inducing turbulent flow across the obstruction and has to be reduced.

The choice of the ideal anaesthetic/sedative medication in critically ill patients with aortic aneurysm causing mediastinal compression remains unclear. Etomidate has proven to be efficacious in maintaining stable hemodynamics; however, etomidate is a potent inhibitor of adrenal corticsol secretion and has been associated with increased mortality in critically ill patients ${ }^{[10-15]}$.

Ketamine can maintain intercostals and chest wall tone well ${ }^{[5]}$. It preserves airway and spontaneous ventilation in addition to it being a good sedative and analgesic. In septic shock ketamine can reduce inotropic supports and has a protective anti-inflammatory effect ${ }^{[2,3]}$. Ketamine use as a sole anaesthetic agent may have number of undesired cardiovascular adverse effects including elevation in blood pressure, heart rate and arrhythmias due to sympathomimetic actions ${ }^{[16-19]}$. The elevated blood pressure and arrhythmogenic properties can have detrimental effects in presence of aortic aneurysm.

Propofol has less influence on neuromuscular function than volatile anesthetics ${ }^{[4,6]}$. However, propofol is associated with haemodynamic instability secondary to reduction in systemic vascular resistance and myocardial depression. This complication will be exaggerated in patients who have pre-existing haemodynamic compromise by sepsis ${ }^{[2,23]}$.

Combination of ketamine and propofol in varying proportion known as ketofol has been studied in a variety of clinical setting, including procedural sedation of endoscopy, bronchoscopy, emergency procedures, endotracheal intubation ${ }^{[24-28]}$.

The adverse effects of ketamine or propofol are dose dependent and tend to oppose each other cardiovascular effects. The combination of ketamine and propofol potentially balanced each other's haemodynamic adverse effects and therefore, after a safer alternative for procedural sedation in critically ill patients. The optimal proportion of ketamine and propofol combination has not been defined yet. Different dose proporation of propofol- ketamine has been investigated ranging from 1:1 to $4: 1$ by weight ${ }^{[29]}$. Most commonly use dose range is either $1: 1$ or 2:1 combination of propofol and ketamine respectively.

The fact that the patient was in sepsis that has limited our use of anesthetic agents as both haemodynamic stability and maintenance of patient airway was at loggerhead with each other. Propofol as mentioned earlier can maintain spontaneous ventilation, but can also produce haemodynamic compromise so ketamine was used to induce anesthesia. We were able to maintain blood pressure as well as have the patient on adequate spontaneous ventilation using propofol infusion with judicious use of vasopressors and intravenous fluids.

\section{Conclusion}

Add mixture of ketamine and propofol (ketofol) is a viable option to maintain spontaneous ventilation with preserve haemodynamics in a septic patient with mediastinal compres- sion requiring procedural sedation.

\section{References}

1. Sendasgupta, C., Sengupta, G., Ghosh, K., et al. Femoro-femoral cardiopulmona bypass for the resection of an anterior mediastinal mass. (2010) Indian J Anaesth 54(6): 565-568.

2. Kurdi, M.S., Theerth , K.A., Deva, R.S. Ketamine: Current applications in anesthesia, pain, and critical care. (2014) Anesth Essays Res 8(3): 283-290.

3. Yoon, S.H. Concerns of the anesthesiologist: anesthetic induction in severe sepsis or septic shock patients. (2012) Korean J Anesthesiol 63(1): 3-10.

4. Rim, S.K., Son, Y.B., Kim, J.I., et al. Propofol and remifentanil total intravenous anesthesia and the preservation of spontaneous respiration for a patient with mediastinal mass. (2013) Korean J Anesthesiol 65(6): 583-584.

5. Vishnu, Datt., Deepak, Tempe. Airway management in patients with mediastinal mass. (2005) Indian J Anaesth 49(4): 344-352.

6. Peter, Slinger. Management of the patient with a central airway obstruction. (2011) Saudi J Anaesth 5(3): 241-243.

7. Lee, J., Rim, Y.C., In, J. An anterior mediastinal mass: delayed airway compression and using a double lumen tube for airway patency. (2014) J Thorac Dis 6(6): E99-E103.

8. Tan, P.C., Esa, N. Anesthesia for massive retrosternal go iter with severe intra thoracic racheal narrowing: the challenges imposed-Acase report. (2012) Korean J Anesthesiol 62(5): 474-478.

9. Malherbe, S., Whyte, S., Singh, P., et al. Total intravenous anesthesia and spontaneous respiration for airway endoscopy in children-a prospective evaluation. (2010) Paediatr Anaesth 20(5): 434-438.

10. Divatia, J.V., Khan, P.U., Myatra, S.N. Tracheal intubation in the ICU: Life saving or life threatening? (2011) Indian J Anaesth 55(5): 470-475.

11. Albert, S.G, Ariyan, S., Rather, A. The effect of etomidate on adrenal function in critical illness: a systematic review. (2011) Intensive Care Med 37(6): 901-910.

12. Bloomfield, R., Noble, D.W. Etomidate, pharmacological adrenalectomy and the critically ill: a matter of vital importance. (2006) Crit Care 10(4): 161.

13. Cherfan, A.J., Tamim, H.M., AlJumah, A., et al. Etomidate and mortality in cirrhotic patients with septic shock. (2011) BMC Clin Pharmacol 11: 22 .

14. Cotton, B.A., Guillamondegui, O.D., Fleming, S.B., et al. Increased risk of adrenal insufficiency following etomidate exposure in critically injured patients. (2008) Arch Surg 143(1): 62-67.

15. Sunshine, J.E., Deem, S., Weiss, N.S., et al. Etomidate, adrenal function, and mortality in critically ill patients. (2013) Respir Care 58(4): 639-646.

16. Reich, D.L., Silvay, G. Ketamine: an update on the first twenty-five years of clinical experience. (1989) Can J Anaesth 36(2): 186-197.

17. White, P.F. Clinical pharmacology of intravenous induction drugs. (1988) Int Anesthesiol Clin 26(2): 98-104.

18. White, P.F., Way, W.L., Trevor, A.J. Ketamine-its pharmacology and therapeutic uses. (1982) Anesthesiology 56(2): 119-136.

19. Jakobsen, C.J., Torp, P., Vester, A.E., et al. Ketamine reduce left ventricular systolic and diastolic function in patients with ischaemic heart disease. (2010) Acta Anaesthesiol Scand 54(9): 1137-1144.

20. Chen, W.H., Lee, C.Y., Hung, K.C., et al. The direct cardiac effect of propofol on intact isolated rabbit heart. (2006) Acta Anaesthesiol Taiwan 44(1): 19-23.

21. Smischney, N.J., Beach, M.L., Loftus, R.W., et al. Ketamine/propofol admixture (ketofol) is associated with improved hemodynamics as an induction agent: a randomized, controlled trial. (2012) J Trauma Acute Care Surg 73(1): 94-101.

22. Yang, H.S., Song, B.G., Kim, J.Y., et al. Impact of propofol anesthesia induction on cardiac function in low-risk patients as measured by intraoperative Doppler tissue imaging. (2013) J Am Soc Echocardiogr 
26(7): 727-735.

23. Smischney, N.J., Beach, M.L., Loftus, R.W., et al. Ketamine/propofol admixture (ketofol) is associated with improved hemodynamics as an induction agent: a randomized, controlled trial. (2012) J Trauma Acute Care Surg 73(1): 94-101.

24. Andolfatto, G., Willman, E. A prospective case series of single-syringe ketamine-propofol (Ketofol) for emergency department procedural sedation and analgesia in adults. (2012) Acad Emerg Med 18(3): 237-245.

25. Dal, T., Sazak, H., Tunc, M., et al. A comparison of ketamine-midazolam and ketamine-propofol combinations used for sedation in the endobronchial ultrasound-guided transbronchial needle aspiration: a prospective, single-blind, randomized study. (2014) J Thorac Dis 6(6): $742-751$.

26. Goh, P.K., Chiu, C.L., Wang, C.Y., et al. Randomized double-blind comparison of ketamine-propofol, fentanyl-propofol and propofol-saline on haemodynamics and laryngeal mask airway insertion conditions. (2005) Anaesth Intensive Care 33(2): 223-228.

27. Nejati, A., Moharari, R.S., Ashraf, H., et al. Ketamine/propofol versus midazolam/fentanyl for procedural sedation and analgesia in the emergency department: a randomized, prospective, double-blind trial. (2011) Acad Emerg Med 18(8): 800-806.

28. Gallo-de Moraes, A., Racedo Africano, C.J., Hoskote, S.S., et al. Case series of ketamine-propofol admixture, "Ketofol", for endotracheal intubations in the critically ill. (2015) Am J Case Rep16:81-86.

29. Amornyotin, S. Ketofol: A Combination of Ketamine and Propofol. (2014) J Anesth Crit Care Open Access 1(5): 00031.
Ommega Online Publishers

Journal Title: Journal of Anesthesia and Surgery (JAS)

Journal Short Name: J Anesth Surg
Journal ISSN: 2377-1364

E-mail: anestheisa@ommegaonline.com

Website: www.ommegaonline.org 